\title{
AÇÕES EDUCATIVAS AMBIENTAIS NO COTIDIANO DE UMA ESCOLA MUNICIPAL DE SANTA MARIA, RS.
}

\author{
Dionisia dos Santos Stein ${ }^{1}$, Thais Scotti do Canto-Dorow ${ }^{2}$ \\ ${ }^{1}$ Especialista em Educação Ambiental \\ tecasstein@yahoo.com.br \\ 2 Docente do Curso de Especialização em Educação Ambiental \\ e do Departamento de Biologia, UFSM \\ thaisdorow@gmail.com
}

\section{RESUMO}

O grande desafio da temática ambiental é abordar questões em sua totalidade, evitando enfoques aos temas isolados, mesmo que relevantes. A prática de Educação Ambiental no cotidiano escolar apresenta alternativas para o envolvimento de toda a comunidade escolar com ações contínuas e não pontuais. Há possibilidades de uma educação ambiental interdisciplinar com o objetivo de problematizar o entendimento, mostrar que o educador tem um papel fundamental nesta nova perspectiva de ensino, criando, recriando, reinventando, fazendo o que não se sabe fazer, deixando-se ensinar com a participação de todos. Sabe-se que são as ações cotidianas que trazem grandes mudanças. Este trabalho traz uma reflexão sobre a educação ambiental na escola e a ética do cuidado. O objetivo principal foi desenvolver ações educativas com alunos do 3 o ano da Escola Municipal de Ensino Fundamental Zenir Aita de Santa Maria, RS, sobre questões envolvendo o meio ambiente, através de palestras, folhetos, passeios ao redor da escola para uma leitura de paisagem, entrevistas com a direção da escola, professores e funcionários. Foram realizadas ações como: lixo no lugar certo, construção de minhocário, relógio do corpo humano com plantas medicinais, aproveitamento de cascas com o bolo de banana. Assim constatou-se que a escola oferece um ambiente favorável para que a Educação Ambiental seja desenvolvida continuamente abrangendo todas as disciplinas, na construção do conhecimento.

Palavras-chave: Ensino Fundamental. Ações Educativas. Meio Ambiente.

\section{ABSTRACT}

The great challenge of the environmental issue is to approach questions in a complete way, avoiding focus on isolated points, even though on the relevant ones. The practice of environmental education in school routines shows alternatives for the involvement of all the school community with continuous actions and not isolated ones. There are possibilities for an interdisciplinary environmental education aiming to problematize the understanding, to show that the educator plays a fundamental role in this new teaching perspective, creating, recreating, reinventing, doing what one does not know what to do, letting oneself learn with everybody's participation. It is known that the everyday actions are the ones that bring great changes. This work brings a reflection on the environmental education in school and the ethics of care. The main objective was to develop educational actions with students of the $3^{\text {rd }}$ year of the Municipal Elementary School Zenir Aita, of Santa Maria, RS, about questions involving the environment through lectures, leaflets, walks around the school for a landscape reading, interviews with the school principal, the teachers and workers. The actions developed were: garbage in the correct place, building of a worm farm, human clock - built with medicinal plants, use of banana peels to 
REMOA

make cakes. Then, it was observed that the school offers a favorable environment for the environmental education to be continuously developed involving all school disciplines, in the construction of knowledge.

Keywords: Elementary School. Educational Actions. Environment.

\section{INTRODUÇÃO}

Muitos são os problemas ambientais que estão ocorrendo no Brasil e no mundo. O efeito estufa, o desmatamento, a pesca predatória, a contaminação das águas, a poluição do ar, os grandes lixões, animais e vegetais em extinção, a destruição do solo são alguns dos inúmeros problemas observados cotidianamente.

Considerando que, muitas das ações em Educação Ambiental na escola são pontuais, que apesar de se repetirem não demonstram estarem comprometidas com o cotidiano, há a necessidade de sensibilizar a comunidade escolar, desenvolvendo a Educação Ambiental de forma contínua e contextualizada com vistas a um futuro com melhor qualidade de vida.

O objetivo desse trabalho foi avaliar a realidade da escola em relação ao cuidado com o meio ambiente, bem como promover ações de educação ambiental. Para tanto foram realizadas entrevistas com a comunidade escolar e, a partir dos resultados, implementadas ações como: reflexão sobre os cuidados e a separação do lixo; construção do minhocário; construção do relógio do corpo humano com plantas medicinais; confeç̧ão de bolo com casca de banana; construção de um painel "Onde deixei meu lixo?"; plantio de flores nos canteiros da escola.

\section{EDUCAÇÃO AMBIENTAL}

É um processo de aprendizagem permanente, baseado no respeito de todas as formas de vida. Ela estimula a formação de sociedades justas, ecologicamente equilibradas com base na solidariedade e no respeito às diferenças (OLIVEIRA, 2000).

A educação ambiental deve envolver pais, alunos, professores e comunidade para a conquista da cidadania. Esse exercício deve ser permanente para o conhecimento das questões ambientais.

\section{Problemas ambientais}

Nossa cultura traz no imaginário a ausência de limites ao que se refere a recursos naturais, água, solo e ar estão à mercê do ser humano, que embora sofrendo as conseqüências de suas ações, continua ignorando o pedido de socorro da natureza.

Entre os maiores causadores estão a poluição, o desmatamento, o uso de produtos químicos no solo que, incorporados em ritmos acelerados, inibe a capacidade de regeneração do meio. $A$ produção de resíduos é excessiva provocando um impacto ambiental.

Há necessidade de um uso equilibrado e mais criterioso dos recursos naturais, para ajustar as relações do homem com o meio ambiente, visando uma sobrevivência mais equilibrada. $O$ estreitamento das relações intra e extra-escolar, vem ser de grande importância na conservação do ambiente principalmente na fase escolar (SOUZA, 2000).

A escola deve aproveitar a experiência social que os educandos possuem como indivíduos e discutir os problemas existentes, como a poluição dos riachos, os lixões e os danos que podem 
STEIN \& DOROW, vol.(4), n4, p. 596-606, 2011.

REMOA

ocorrer à saúde das pessoas. É através de um novo ideário comportamental, tanto individual quanto coletivo que a educação ambiental busca se firmar (OLIVEIRA, 2000).

Nesse trabalho, defende-se que a educação ambiental na escola deve fazer parte de todos os conteúdos, trabalhando com situações problemas, buscando caracterizá-las e contextualizá-las. A questão ambiental não pode estar contida apenas ao campo específico de uma única ciência, ela chama a depor diversos campos do saber (GONÇALVES, 1990).

\section{Educação Ambiental no cotidiano escolar}

A solução dos problemas ambientais não se restringe apenas à proteção das florestas, mas através do desenvolvimento de ações que possibilitem uma melhor qualidade de vida, hoje ameaçada. Essas informações devem ser discutidas na escola, na família e na comunidade.

Freire (1995, p. 80) diz que, "mudar é difícil, mas é possível", para tanto é necessário conhecer a realidade, através do diálogo, desafiando o grupo para o conhecimento de sua história. Dessa forma pode-se fazer uma projeção do que está sendo e o que pode ser feito no futuro.

Daí a importância de não acontecer somente ações pontuais, mas que transcenda o ambiente escolar, atingindo as comunidades nas quais residam alunos, professores, funcionários, buscando modificações de atitudes, valores, provocando uma reflexão que desperte toda a sociedade, visando a sensibilização e mudança de postura quanto às questões ambientais.

A escola deve proporcionar situações onde o aluno possa interagir, coordenar suas ações, ser seu próprio agente na aquisição de conhecimentos e habilidades. Esses valores devem ser compartilhados em comunidade, assim a criança passa a ser integrante e construtora de mundos (BARCELOS, 2008).

Segundo Thiollent (2000), a pesquisa social deve estar associada a uma ação ou resolução de um problema coletivo, no qual os pesquisadores e participantes estão envolvidos de modo cooperativo e participativo.

Para que isso aconteça são necessárias mudanças de atitudes, de pensar na mente e no coração. É preciso encontrar caminhos, respeitando a vida, os povos, a biodiversidade e sua beleza.

\section{METODOLOGIA}

O estudo foi realizado com 19 alunos do 30 ano da Escola Municipal de Ensino Fundamental Zenir Aita de Santa Maria, no período de maio e junho de 2011. A escolha desses alunos foi por entendermos que é importante a interação das crianças com o meio ambiente, desde pequenos, através de ações e reflexões. A escola conta atualmente com 190 alunos, 20 professores e 3 funcionários.

A pesquisa deste trabalho foi de abordagem qualitativa, do tipo pesquisa-ação, conforme Thiollent (2000).

Inicialmente, foi realizada a coleta de dados com o objetivo de reunir informações de como o trabalho em educação ambiental estava sendo desenvolvido na escola. Seguem os roteiros de entrevistas semi estruturadas direcionadas à direção, a professores, a representantes do Conselho de Pais e mestres (CPM) e funcionários da escola (Quadros 1 a 3). 
STEIN \& DOROW, vol.(4), n4, p. 596-606, 2011.

1 Como a escola vem trabalhando a Educação Ambiental?

2 Qual a periodicidade com que a escola costuma trabalhar a Educação Ambiental?

3 Qual sua visão como educador sobre o comportamento do aluno em suas ações no cotidiano escolar, referindo-se a Educação Ambiental?

4 Qual o comprometimento dos demais segmentos da comunidade escolar em relação à Educação Ambiental?

5 A escola costuma se engajar em campanhas ou debates relacionados ao meio ambiente?

6 Como educador, gostaria de desenvolver na escola um trabalho contínuo em Educação Ambiental?

Quadro 1 - Roteiro de entrevista para professores e equipe diretiva da escola.

1 Como representante dos pais na escola, qual sua visão sobre o trabalho com os alunos em Educação Ambiental?

2 Gostaria que a escola trabalhasse continuamente a Educação Ambiental, envolvendo toda a comunidade escolar?

Quadro 2 - Roteiro de entrevista para o Conselho de Pais e Mestres (CPM) da escola.

1 Como funcionário(a) da escola, acha importante trabalhar a Educação Ambiental continuamente na escola?

2 O que é feito das cascas e folhas usadas na cozinha e do lixo recolhido na escola?

Quadro 3 - Roteiro de entrevista para os funcionários da escola.

Com base nos dados coletados nas entrevistas, foram organizadas as seguintes ações:

- Palestra direcionada aos pais, alunos e professores sobre os cuidados com o meio ambiente, através de questionamentos sobre o que entendem por meio ambiente. Quem faz parte desse meio?

Podemos jogar tudo o que não queremos no solo? E o ambiente da sala de aula e o de nossa casa, é o mesmo meio ambiente? O que podemos fazer para melhorar o nosso planeta?

- Caminhada ao redor da escola para os alunos observarem o ambiente; o que eles enxergam, se existe lixo no solo e de que tipo? Existem árvores? Tem esgoto aberto na rua?

- Estudo e reflexão sobre os cuidados com o lixo, bem como a separação do mesmo; todo lixo pode ser reaproveitado, lixo seco, lixo orgânico, a importância da separação que vai facilitar para quem recolhe esse lixo. O lixo orgânico pode ser usado como adubo, com isso evita-se de ficar jogado a céu aberto aumentando a proliferação de insetos e roedores, causando doenças à população.

- Construção do minhocário; usando um pequeno espaço na escola, com alguns tijolos, que estão sem uso no pátio do colégio, foi fechado um quadrado no chão e as sobras de cascas e folhas usadas na cozinha da escola serviram de alimento para as minhocas californianas.

- Construção de um painel "Onde deixei meu lixo?"; para mostrar aos educandos que produzimos lixo e não percebemos a quantidade.

- Construção do relógio do corpo humano com plantas medicinais, usando plantas que a família conhece e ingere como chá; através de um questionário coletar informações sobre o uso de plantas medicinais pela família. 
REMOA

\section{Monografias Ambientais}

(e-ISSN: 2236-1308)

- Confecção de bolo com casca de banana; utilizando a cozinha da escola, para demonstrar como é feito, para a merendeira, professora e alunos participantes do estudo.

- Plantio de flores no canteiro da escola; com alguns pais que queiram participar ajudando no preparo do canteiro e alunos do 30 ano.

\section{RESULTADOS E DISCUSSÃO}

Diante dos procedimentos metodológicos adotados para a realização desta pesquisa, constatou-se que a educação ambiental na escola vem sendo trabalhada de forma contínua nos anos iniciais, mas não com o comprometimento de toda a comunidade escolar.

A seguir, algumas respostas da entrevista realizada com a equipe diretiva, professores, representante do CPM e funcionário.

\section{Como a escola vem trabalhando a educação ambiental?}

A equipe diretiva respondeu:

Entrevistado "A":

- Através de alguns projetos, formação, palestras com pais, alunos e professores. Inserida dentro do currículo escolar desenvolvido em todas as disciplinas de 1ㅇ ao 9o ano.

Resposta do entrevistado "B":

- Durante todo o ano o tema é abordado, dando ênfase maior na semana do meio ambiente.

Resposta do entrevistado " $\mathrm{C}$ ":

- Com conscientização.

A escola já possui um trabalho em Educação Ambiental com os educandos através de projetos, sendo o professor de Ciências da escola que atua com seus alunos no 60 ano. Um dos trabalhos realizados com toda a comunidade escolar foi à separação do lixo, facilitando o entendimento sobre a importância da coleta seletiva e que é importante o cuidado com a natureza dentro e fora de casa. Em relação a isso, Boff (1999, p. 134) diz que "para cuidar do planeta precisamos todos passar por uma alfabetização ecológica e rever nossos hábitos de consumo". Dessa forma, temos de primar pela ética do cuidado, remetendo-a a necessidade de um planeta sustentável.

\section{Qual a periodicidade com que a escola costuma trabalhar a Educação Ambiental?}

Resposta do entrevistado " $A$ ":

- Durante o ano letivo e não somente no dia 05 de junho.

Resposta do entrevistado " $B$ " $\mathrm{e}$ " $\mathrm{C}$ ":

- Durante todo o ano o tema é abordado, dando ênfase maior na semana do meio ambiente.

Qual a sua opinião como educador, referindo-se a Educação Ambiental, sobre o comportamento do aluno em suas ações no cotidiano escolar?

Resposta do entrevistado "A":

- Deveriam ter comportamentos adequados, conforme as instruções que recebem no âmbito escolar. Também deveriam preocupar-se com a quantidade de lixo que se acumula no nosso dia a dia e dar um fim correto para os mesmos.

Resposta do entrevistado "B": 
REMOA

\section{Monografias Ambientais}

(e-ISSN: 2236-1308)

- Ele fica limitado à separação dos resíduos sólidos produzidos no ambiente escolar.

Resposta do entrevistado " $C$ ":

- Eles não são disciplinados, não vem de casa para que a escola trabalhe melhor.

Para Freire (1996, p. 32) "não haveria criatividade sem a curiosidade que nos move e nos põe cientemente impacientes diante do mundo que não fizemos, acrescentando a ele algo que fazemos". E assim, é preciso despertar no aluno o senso crítico, o conhecimento, para que ele possa fazer suas escolhas, desenvolver atitudes que lhes permitam adotar uma posição consciente diante de questões relacionadas à coletividade.

\section{Como é o comprometimento dos demais segmentos da comunidade escolar com relação à Educação Ambiental?}

A resposta da equipe diretiva foi unânime em afirmar que:

- Não tem projeto de parceria.

- Faz-se necessário um trabalho maior para que todos se sintam engajados e comprometidos com o tema na escola.

É urgente um trabalho de conscientização com a comunidade escolar sobre o ambiente em que vivemos. Para Boff (1995) os danos são planetários, atingindo o solo, o ar, as águas, o clima, a flora, a fauna e a vida humana. São necessários, para tanto, a participação de todos. O conhecimento é fundamental para um resultado concreto e duradouro, visando à conscientização para a preservação e conservação do meio.

\section{O educador gostaria de desenvolver na escola um trabalho contínuo em Educação Ambiental?}

Resposta do entrevistado "A" e "B":

- Sim, oferecendo oportunidades sempre que possível para a realização de projetos.

Resposta do entrevistado " $\mathrm{A}$ ":

- A escola tem projetos nessa área que necessita de uma maior participação de todos os professores para serem trabalhados de forma multidisciplinar.

Resposta do entrevistado " $\mathrm{C}$ ":

- Gostaria, é de extrema necessidade, a dificuldade está passar para os pais. As ações feitas na escola, não tem seguimento em casa, não objetivando o trabalho só em sala de aula. A Educação Ambiental deveria ser colocada como disciplina.

Trabalhar a educação ambiental de forma contínua é buscar mudanças de hábitos na comunidade escolar e buscar envolver as forças vivas da comunidade para um entendimento sobre o meio em que vivem. Boff $(2001$, p. 9) diz que:

hoje nos encontramos numa fase nova na humanidade. Todos estamos regressando a casa comum, a Terra: os povos, as sociedades, as culturas e as religiões. Todos trocamos experiência valores. Todos nos enriquecemos e nos completamos mutuamente [...].

É importante que a escola valorize, conheça e respeite os saberes dos alunos, enriquecendo, dessa forma, o entendimento escola - meio ambiente.

A representante do CPM da escola foi questionada sobre: 
Qual a sua visão sobre trabalhar com os alunos a Educação Ambiental? Gostaria que a escola trabalhasse continuamente o tema, envolvendo toda a comunidade escolar?

Resposta da representante do CPM:

- Acho importante mostrar a realidade para os alunos, através de passeios, ver as árvores nativas e não nativas, mostrar o que devem e o que não devem deixar no meio ambiente. Acho importante trabalhar continuamente o tema na escola.

Segundo Freire (1995, p. 28), "não há, por isto mesmo, possibilidade de dicotomizar o homem do mundo, pois que não existe um sem o outro" e, assim, desenvolver neles o respeito pelo meio ambiente. Para isso é necessário promover atividades em que todos estejam em contato com a natureza e aprendam a valorizar o mundo em que vivem. Acredita-se que tais atividades são importantes e representam uma forma de aprendizado concreto, saudável e criativo.

A funcionária da foi questionada sobre:

Qual a importância de trabalhar continuamente a Educação Ambiental na escola?

Resposta da funcionária da escola:

- Muito importante, os alunos precisam ter noção do ambiente escolar.

- O lixo produzido na sala de aula fica no chão.

E o que é feito das cascas e folhas usadas na cozinha e do lixo recolhido na escola? Resposta da funcionária da escola:

- Vai tudo no lixo normal, misturado.

A questão ambiental está na forma como a sociedade interage com a natureza, colocando a necessidade de uma maior reflexão sobre o lugar que esta ocupa no campo do conhecimento (GONÇALVES, 1990). Assim, o ser humano precisa entender que ele é fator determinante junto ao meio ambiente, sendo este, o único ser responsável pela construção ou destruição do planeta.

\section{AÇõES DESENVOLVIDAS}

\section{Construção do minhocário}

Com a separação do lixo seco do orgânico foi possível a construção do minhocário (Figura 1), com a participação dos alunos, professora e da merendeira foi colocado no espaço já preparado, folhas, cascas, de produtos utilizados na confecção da merenda. Foi explicado aos educandos sobre a importância da utilização das minhocas para que estas ajudem na decomposição do lixo.

Para a construção do minhocário não houve custos, sendo permitido, aos alunos interessados, levarem minhocas para a construção de um minhocário caseiro. 


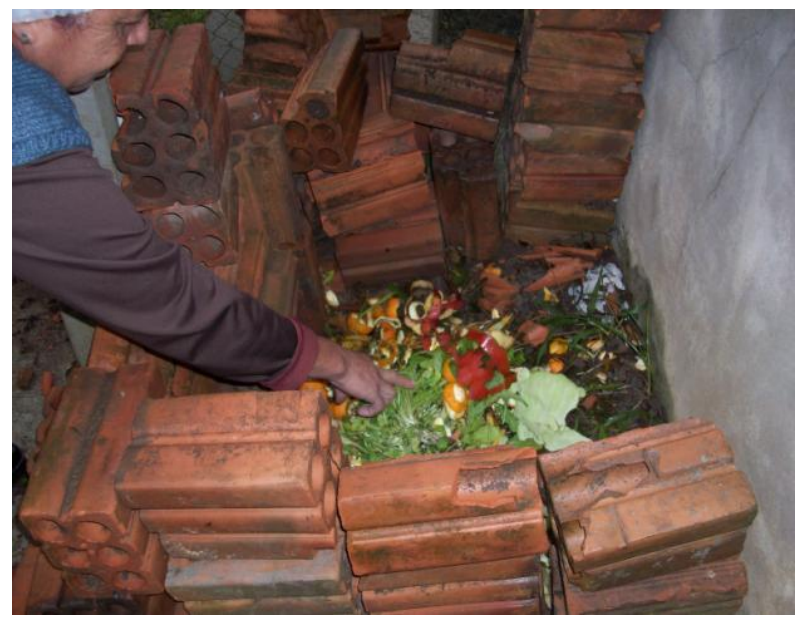

Figura 1 - Construção do minhocário na escola.

\section{Reconstrução do lixo}

A reconstrução do lixo na sala de aula teve como objetivo chamar a atenção dos educandos sobre a colocação do lixo no lugar certo. $O$ cesto de lixo foi customizado para ficar atrativo para servir de incentivo na separação do lixo não só na escola, mas também em casa.

\section{Construção do painel “Onde deixei meu lixo?”}

Com a construção do painel pelos alunos foi trabalhada a idéia de que o acúmulo de lixo produzido pelo homem traz conseqüências desastrosas ao nosso planeta.

\section{Música "Meio Ambiente"}

A música "Meio Ambiente" de Francês R. Pinto, foi utilizada para melhor entendimento sobre a natureza. Um momento de união entre toda a sala de aula, através de gestos como abrir os braços, correr no lugar, motivou reflexão e descontração para continuar o tema na sala de aula.

\section{Relógio do Corpo Humano}

A (Figura 2) mostra a importância do conhecimento das plantas medicinais, o cuidado, e a preservação das mesmas. 


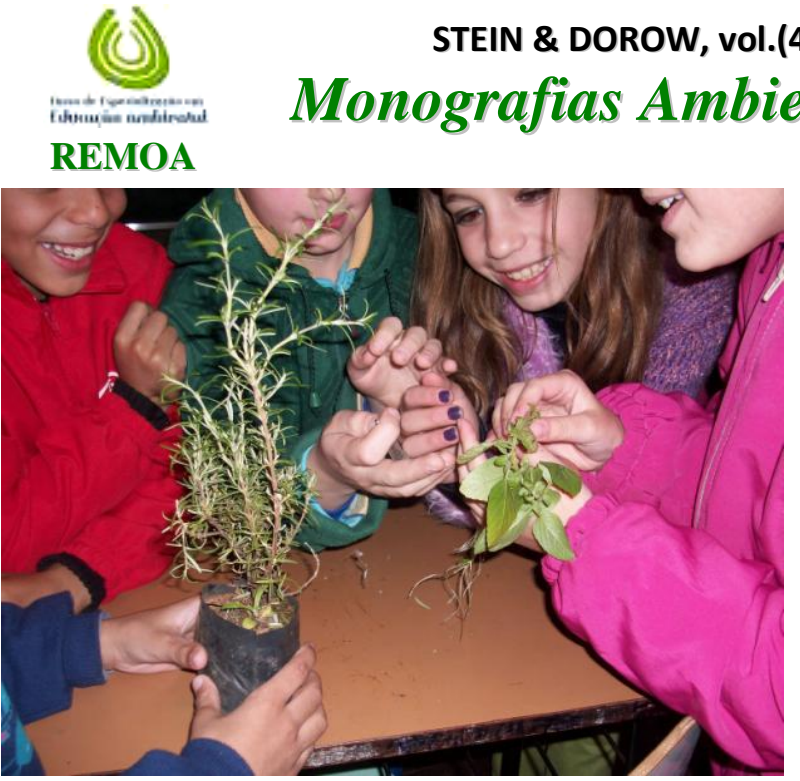

Figura 2- Conhecimento de plantas medicinais.

Através de um questionário (Apêndice A) realizado pelos alunos e direcionado aos pais, foi possível saber quais as plantas medicinais mais usadas pela família. As salientadas foram: Macela, Cidró, Funcho, Tansagem, Folhas de Laranjeira, Poejo, Boldo, Losna e Manjericão. Para que os alunos conhecessem mais as plantas foi construído o relógio do corpo humano, no qual foi mostrada a ação de cada planta nos órgãos do corpo. Para a construção do relógio foi utilizado um quadro de tecido o qual mostra as horas de maior atividade diária de cada órgão num intervalo de duas horas, como: fígado da $01 \mathrm{~h}$ às $03 \mathrm{~h}$; pulmão das $03 \mathrm{~h}$ às $05 \mathrm{~h}$; intestino grosso das $05 \mathrm{~h}$ às $07 \mathrm{~h}$; estômago das 07 às 09h; baço e pâncreas das $09 \mathrm{~h}$ às $11 \mathrm{~h}$; coração das $11 \mathrm{~h}$ às $13 \mathrm{~h}$; intestino delgado das $13 \mathrm{~h}$ às $15 \mathrm{~h}$; bexiga das $15 \mathrm{~h}$ às $17 \mathrm{~h}$; rins das $17 \mathrm{~h}$ às $19 \mathrm{~h}$; circulação das $19 \mathrm{~h}$ às $21 \mathrm{~h}$; sistema digestivo, sistema excretor e sistema respiratório das $21 \mathrm{~h}$ às $23 \mathrm{~h}$.

O quadro foi construído de forma que pudesse ser pendurado na parede, podendo ser movimentado de uma sala para outra se houver interesse por parte dos educadores. Está comprovado que aproximadamente $80 \%$ a $85 \%$ da população mundial tem o hábito de utilizar plantas medicinais como remédio (FERRO, 2006).

\section{Bolo com Casca de Banana}

Para o entendimento do aluno sobre o aproveitamento integral dos alimentos foi realizada a receita do bolo com casca de banana. Foi distribuída a receita do bolo, houve questionamentos por parte deles, como era colocada a casca, se seria bom para comer. Foi utilizada a cozinha da escola, bem como alguns materiais como forno, liquidificador, bacias, forma. Teve início com a limpeza das bananas em água corrente, retirando-se as cascas para serem utilizadas. $O$ bolo foi compartilhado com os professores presentes na escola naquele momento e aprovado, também pelos alunos.

\section{CONCLUSÃO}

Com este estudo procurou-se mostrar a importância em se trabalhar a Educação Ambiental no cotidiano escolar continuamente, enfatizando para a comunidade escolar, que somos responsáveis pelas ações que fizemos ao meio ambiente. Através de entrevista realizada na comunidade escolar foi possível saber como a escola vinha trabalhando a Educação Ambiental. 
REMOA

As ações desenvolvidas na escola como a separação do lixo orgânico, a construção do minhocário, o relógio do corpo humano, divulgar e preservar as plantas medicinais, assim como a construção do painel "Onde deixei meu lixo?", a reconstrução do lixo na sala de aula, o bolo com casca de banana, folhetos explicativos sobre os cuidados com o meio ambiente são exemplos de ações que poderão ser discutidas continuamente na escola, adaptando, recriando, envolvendo educandos e família.

\section{CONSIDERAÇÕES FINAIS}

A escola possui um excelente espaço para a formação de cidadania ambiental, atuando no cotidiano escolar formal e não formal, desafiando a todos para a participação na resolução de problemas, articulando a escola para os conhecimentos locais, regionais e globais.

Essas pequenas ações que podem ser desenvolvidas na escola são de grande importância no cotidiano. Portanto, para desenvolver a Educação Ambiental no cotidiano da Escola, o ensino aprendizagem deve estar pautado no conhecimento da realidade do aluno, na vivência e convivência, buscando desenvolver na comunidade escolar o senso crítico e suas competências, para que estas sejam usadas para uma melhor qualidade de vida, visando à preservação do ecossistema.

Para haver mudança de postura quanto às questões ambientais, é essencial o comprometimento de toda a comunidade escolar, na continuidade e manutenção de projetos benéficos ao equilíbrio ambiental.

Os resultados apontarão para uma qualidade de vida melhor, acreditando que um novo mundo ainda é possível.

\section{REFERÊNCIAS}

BARCELOS, Valdo. Educação Ambiental: sobre princípios, metodologias e atitudes. Petrópolis, RJ: Vozes, 2008 (Coleção Educação Ambiental).

BOFF, Leonardo. Ecologia: Grito da Terra: grito dos pobres. Ática: São Paulo, SP, 1995.

. Saber Cuidar: ética do humano-compaixão pela Terra. Petrópolis, RJ: Vozes, 1999.

. O Casamento entre o céu e a terra. Rio de Janeiro: Salamandra, 2001.

FERRO, D. Fitoterapia: conceitos clínicos. São Paulo: Atheneu, 2006.

FREIRE, Paulo. Pedagogia da autonomia: saberes necessários à prática educativa. São Paulo: Paz e Terra, 1996.

Extensão ou comunicação? Rio de Janeiro: Paz e Terra, 1995.

GONÇALVES, C. W. P. Possibilidades e limites da Ciência e da Técnica diante da Questão Ambiental. In: SEMINÁRIO UNIVERSIDADE E MEIO AMBIENTE. DOCUMENTOS BÁSICOS, 2, 1990, Brasília, DF: Anais...Brasília, DF: 1990.

OLIVEIRA, E.M. de. Educação Ambiental: uma possível abordagem. 2. ed. Brasília, DF: IBAMA, 2000.

SOUZA, A. K. A relação escola-comunidade e a conservação ambiental. 2000. 89 fl. Monografia (Especialização em Educação Ambiental) - Universidade Federal da Paraíba, João Pessoa, 2000.

THIOLLENT, M. Metodologia da pesquisa-ação. 10. ed. São Paulo: Cortez, 2000. 
STEIN \& DOROW, vol.(4), n4, p. 596-606, 2011.

Monografias Ambientais $\quad$ (e-ISSN: 2236-1308)

REMOA

APÊNDICE A - Entrevista com a família sobre o uso de plantas medicinais.

1 Costumam tomar chá para alguma doença?

2. Que tipo de planta medicinal usam?

3. Aonde conseguem essas plantas?

4. Costumam cultivar plantas medicinais em casa? 